\title{
Wealth inequality: The physics basis
}

A. Bejan and M. R. Errera

Citation: Journal of Applied Physics 121, 124903 (2017); doi: 10.1063/1.4977962

View online: http://dx.doi.org/10.1063/1.4977962

View Table of Contents: http://aip.scitation.org/toc/jap/121/12

Published by the American Institute of Physics

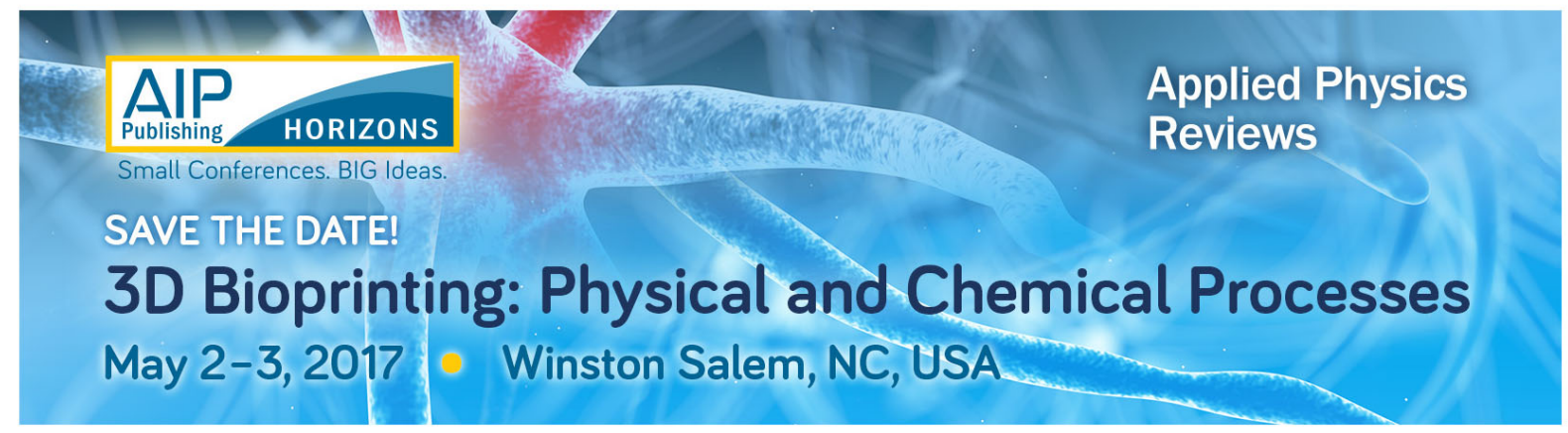




\title{
Wealth inequality: The physics basis
}

\author{
A. Bejan ${ }^{1}$ and M. R. Errera ${ }^{2}$ \\ ${ }^{1}$ Duke University, Department of Mechanical Engineering and Materials Science, Durham, \\ North Carolina 27708-0300, USA \\ ${ }^{2}$ Federal University of Paraná, Department of Environmental Engineering, Curitiba, Parana, 81531-980, \\ Brazil
}

(Received 7 November 2016; accepted 21 February 2017; published online 28 March 2017)

\begin{abstract}
"Inequality" is a common observation about us, as members of society. In this article, we unify physics with economics by showing that the distribution of wealth is related proportionally to the movement of all the streams of a live society. The hierarchical distribution of wealth on the earth happens naturally. Hierarchy is unavoidable, with staying power, and difficult to efface. We illustrate this with two architectures, river basins and the movement of freight. The physical flow architecture that emerges is hierarchical on the surface of the earth and in everything that flows inside the live human bodies, the movement of humans and their belongings, and the engines that drive the movement. The nonuniform distribution of wealth becomes more accentuated as the economy becomes more developed, i.e., as its flow architecture becomes more complex for the purpose of covering smaller and smaller interstices of the overall (fixed) territory. It takes a relatively modest complexity for the nonuniformity in the distribution of wealth to be evident. This theory also predicts the Lorenz-type distribution of income inequality, which was adopted empirically for a century. Published by AIP Publishing. [http://dx.doi.org/10.1063/1.4977962]
\end{abstract}

\section{INTRODUCTION}

Physics impresses all of us with its laws, which are few, precise, and universally applicable. Can biology and economics be a more precise and predictive science, like physics? ${ }^{1-3}$ Scientists have long recognized the need to discern the physics that underlies economy. ${ }^{4-6}$ Recognized was also the need to formulate a physics principle that accounts for design evolution everywhere. ${ }^{1-17}$

Recent work with the constructal law ${ }^{1-3,8}$ has shown that economic activity is closely correlated with the movement of all the streams of society. This is made evident by Fig. 1. The annual domestic economic activity of a country (the Gross Domestic Product, or GDP) is proportional to the physical movement measured as the amount of fuel consumed annually with purpose in that country. Why, because fuel generates power, power drives the movement, and movement dissipates the power (Fig. 2).

More economic activity means more fuel consumption, not less. All the dots are climbing on the diagonal in Fig. 1. This evolutionary aspect is documented by the data ${ }^{18}$ plotted in Fig. 3. Improvements in efficiency (the middle curve) lead to more fuel consumption, not to less fuel consumption. The improvements are akin to the removal of obstacles in the flow design, and once removed the obstacles are forgotten. The new design without obstacles "flows better," and it persists in time. It is adopted by everyone. This consequence is clear in view of the constructal law, ${ }^{1,8}$ and it answers an old puzzle known in economics as Jevon's paradox. ${ }^{19}$ The puzzle was that the more efficient use of coal in the industrialized world in the $1800 \mathrm{~s}$ actually increased the consumption of coal and other resources, instead of "saving" them. Figure 3 shows that the world energy consumption and the world energy use per capita continue to increase even though the population weighted energy use per GDP has decreased since 1990 as the world technology for power becomes more efficient.

\section{DEFINITIONS}

Because of the unification of physics and economics advanced in this article, it is necessary to begin with a set of unambiguous definitions of the terms used:

Movement is the change in the location of the material from one spot to another on the earth's surface. Movement is mostly in the horizontal direction. The movement is greater when the mass moved (M) and the distance traveled (L) are greater. The physical measure of movement is the product ML. Movement is present at all discernible scales, from water in the smallest rivulets to water in the biggest rivers and the trucks on the longest and widest highways.

An alternative physical measure of the movement $\mathrm{ML}$ is the work spent to cause the movement. As we show in the Movement section of this article, the work spent is the product FL, where F is the horizontal force overcome by the mover. In all media (land, sea, and air), the force scales as the weight of the mass $\mathrm{M}$; therefore, $\mathrm{F} \sim \mathrm{Mg} .{ }^{1,20,21}$ The work spent has the scale MgL.

A third physical measure of movement is the amount of "fuel" (fossil, renewable, and food) used for generating the work spent in order to create the movement. This third measure is proportional to the first two. The amount of fuel used is proportional to the amount of useful energy (exergy) contained in the amount of fuel. ${ }^{22}$ The spent exergy is proportional to the work produced and consumed during the movement. In the limit where the energy conversion machine that produces work from fuel operates reversibly, the exergy spent is equal to the work produced and spent during movement. In an actual machine, the generated work is a 

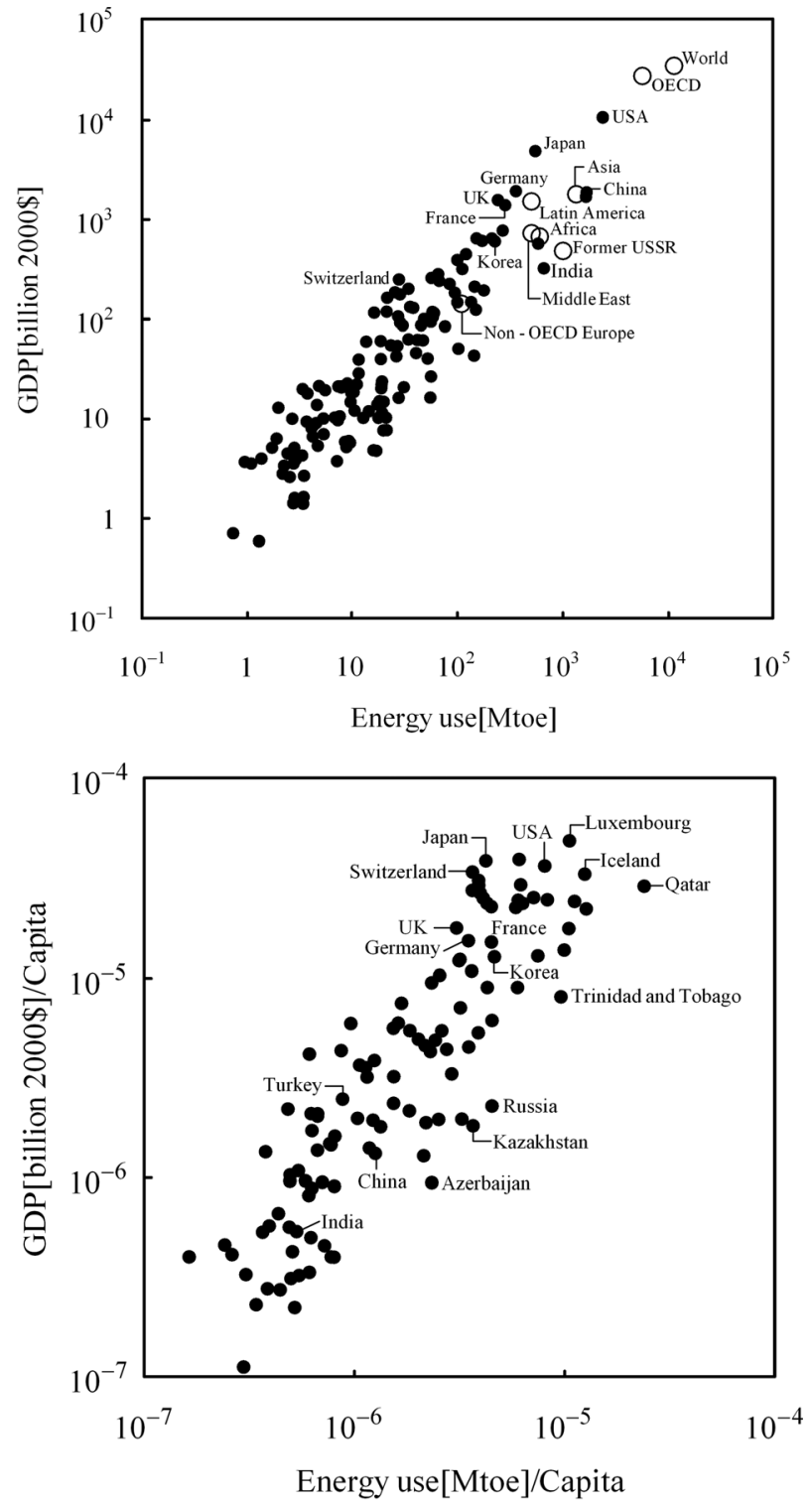

FIG. 1. Gross Domestic Product of regions and countries all over the globe versus annual consumption of fuel, aggregate (top) and per capita (bottom). ${ }^{1}$

significant fraction of the fuel exergy content. Important is that according to the method of scale analysis, ${ }^{23}$ the work and the fuel exergy have the same scale.

In sum, more movement represents more work that is spent, and more work spent represents more fuel that is consumed. Movement is defined as displacement against forces that resist the displacement. Nothing moves unless it is pushed or pulled (Fig. 2).

Wealth is a common term that represents the availability of valuable (purposeful) material resources. It is a measure of the assets of value owned by an economic entity. Key is the word "valuable," and in this article we rely on the physical meaning and measure of wealth. In the doctrine of economics, wealth is described in dollar terms, as on the ordinate of Fig. 1. During the past two decades, in the field of the constructal law theory and design, ${ }^{1-3,8}$ it was shown that the annual wealth of a population or territory is essentially proportional to the useful energy (or work and movement) generated
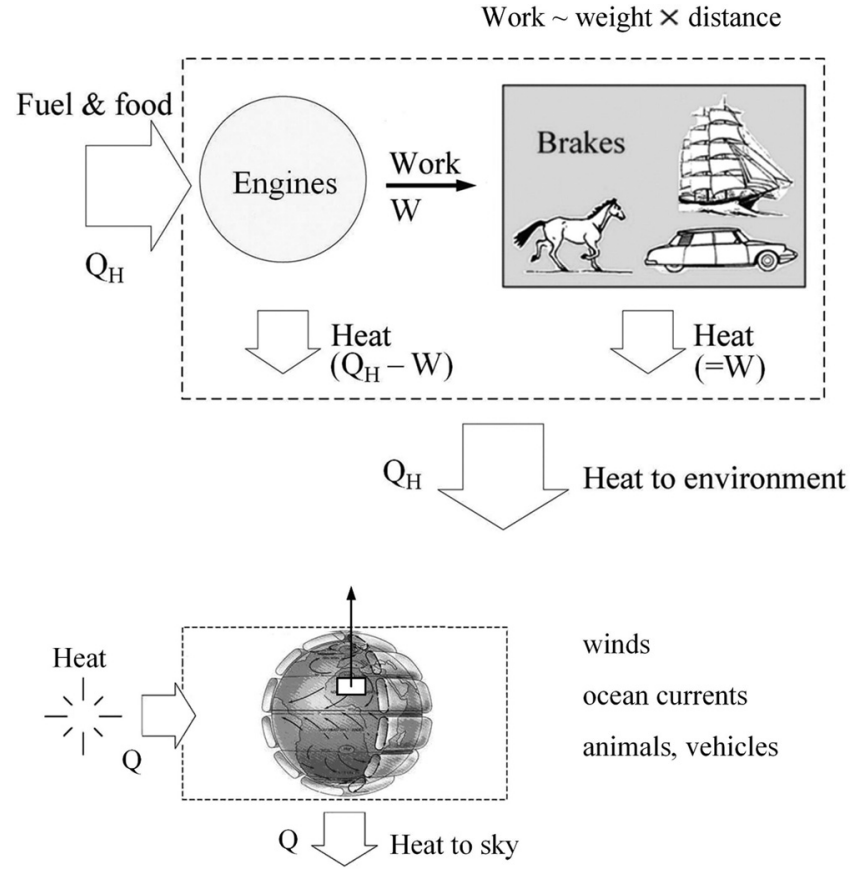

winds

ocean currents

animals, vehicles

FIG. 2. The whole earth is an engine + brake system, containing innumerable smaller engine + brake systems (winds, ocean currents, animals, and human and machine species, e.g., vehicles). ${ }^{1}$

annually by that group or on that territory. This discovery is summarized in Figs. 1 and 3, and it is of empirical nature.

This finding is pivotal for the physics discipline because it shows that the economics concept of wealth has a physics basis, which is measurable as work, fuel consumed, or movement effected by fuel, food, and work. This is the unification - the connection-of economics and physics. The equivalence between wealth and movement is correct in the broadest sense: outliers exist, and undoubtedly the equivalence is evolutionary because wealth and fuel use are increasing over time. As noted earlier, all the dots are

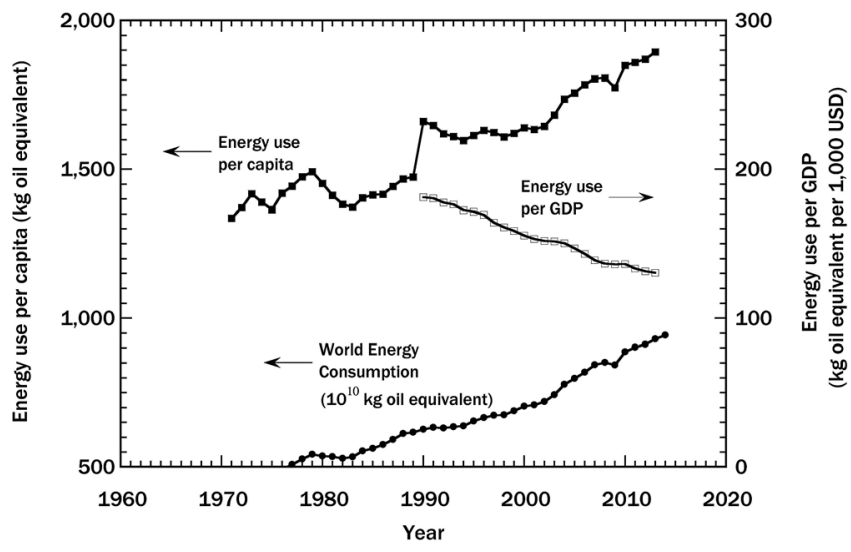

FIG. 3. The evolution of fuel energy use and wealth since 1971: total final energy consumption $\left(10^{10} \mathrm{~kg}\right.$ oil equivalent), world energy use per capita ( $\mathrm{kg}$ oil equivalent per capita) weighted by population, and energy use in the economy (kg oil equivalent per \$1,000 GDP, held constant with 2011 international purchase power parity, PPP). Source: IEA Statistics C OECD/IEA 2014-IEA, 2016 and The World Bank Development Indicators. ${ }^{18}$ The International Energy Association states the total energy final use as the sum of the consumption in the end-use sectors. The methods and procedures are explained in Ref. 18. 
migrating upward (one way) along the bisector in both frames of Fig. 1.

Nonuniform distribution is used here descriptively, to account for the physical (natural) occurrence of movement (or fuel use, work, and wealth) that is not allocated equally over a population or a territory. This aspect of nature is widely recognized as hierarchy: few large and many small move, flow, and "live" together. ${ }^{1,8,14-16}$ We see this in the flowing and morphing architectures of river basins, animal populations (the food chain), social organization, streets in the city, highways, and the global air traffic and commerce.

Inequality. The nonuniform hierarchical distribution of movement on the earth is commonly described as unequal distribution or inequality. This alternative description is particularly common when it comes to the physical equivalents of movement discussed above, namely, fuel use and wealth.

"Inequality" is the oldest and most divisive observation about us, as members of society. ${ }^{24}$ There is no topic more burning than this today, and this is why the theoretical step advanced in this paper is timely. This paper uses physics to predict the natural occurrence of hierarchical movement and wealth on earth.

Constructal law is a 20-year old contribution to thermodynamics, in which the occurrence and evolution of flow configuration is recognized as a universal phenomenon in nature (bio and nonbio), which is summarized as a law of physics. The constructal law states that "For a finite-size flow system to persist in time (to live) it must evolve freely in such a way that it provides easier access to the imposed (global) currents that flow through it." ${ }^{25-27}$ Reviews of this growing field are published regularly by independent authors, for example, Refs. 2, 3, 12-16, and 28-37. This literature is showing that flow systems that spread over (or collect from) an area or volume evolve toward architectures that provide greater access and exhibit hierarchy.

The physics literature $e^{8,15,22,31}$ shows that the constructal law is a law of physics because it accounts with one statement for the numerous (and contradictory) ad-hoc principles of optimality and self-organization, such as minimum entropy production, maximum entropy production, minimum flow resistance, maximum flow resistance, minimum travel time, minimum effort, uniform distribution of stresses, maximum growth rate of flow disturbances (i.e., turbulence), maximum power, etc. In particular, Reis ${ }^{31}$ showed that the constructal law accounts for all the phenomena that are currently associated with the contradictory principles of minimum and maximum entropy production.

The constructal-law literature also shows how flow architectures evolve to "liberate" their flows, to flow better, longer, and farther. In the human sphere, the evolution of technology has the effect of liberating the movement of people and their belongings. The urge of every moving thing is to have more access to movement into and over its available space. For modern humans, this is made possible through technologies that evolve, for example, the technology of power generation. Improvements in power-plant efficiency lead to greater movement and fuel use, not less. It was shown that the constructal law is the physics basis for Jevon's paradox. ${ }^{1}$ The time arrow that points upward along the diagonal of Fig. 1 is itself a manifestation of the natural tendency summarized as the Constructal law.

River basins. Since the $1930 \mathrm{~s}$, the hierarchy of rivers and tributaries in a river basin is well documented in geophysics and is summarized in the form of rules (or "laws") named after Horton, Melton, and Hack. ${ }^{38}$ The best known rule is Horton's law of stream numbers, which is based on the statistics of river basins all over the world: the number of tributaries to a larger (mother) river falls in the range of 3-5. Models of river basins assign a constant value to this number, even though there is no real-world river basin with a universal (precise) number of tributaries.

Lower and upper bounds. The scales of the constructions made in the models described later in this paper (Figs. 5 and 9) have finite lower and upper bounds. Finiteness is an intrinsic feature of the evolutionary design phenomenon captured by the constructal law (note the presence of "finite size" in the constructal law statement, which rules out the infinitesimal and the infinite).

In a river basin, the lower bound is the area of the two hill slopes that feed the first rivulet, and the upper bound is the down-slope territory between the mountain range and the coastline. In urban design, the lower and upper bounds are the area occupied by one house (covered by walking) and the area of the city (covered by riding on one or more vehicles).

Fuel technology evolution. The evolutionary nature of the alignment shown in Figs. 1 and 3 includes many effects that depend on time: discoveries of new fuels (fossil and renewable), implementation of new power generation technologies, and national energy policies such as renewables, decarbonization, government, and international trade agreements. Such complexities add even more strength to the "broad" reading of Figs. 1 and 3, as a translation of the broad term "wealth" into precise physical terms and concrete measures (useful energy, work, and movement).

The data plotted in Fig. 1 are from the International Energy Agency, and refer to the year 2006. ${ }^{39}$ Newer reports ${ }^{40,41}$ show that human related energy expenditure is not uniform over the planet. The methods and means used in Refs. 40 and 41 are discussed in the Appendix of these reports. Human energy expenditure is an overall index, and it cannot be associated with single events. Nevertheless, the indices are adopted widely by the scientific community. The World Bank also shows that the economic activity and thus the production of wealth are not distributed uniformly.

\section{MOVEMENT}

In the simplest terms, movement on the earth's surface is measured as the amount of fuel spent in order to drive the movement. The fuel spent is proportional to $\mathrm{FL} / \eta$, where $\mathrm{F}$ is the horizontal force of resistance overcome by the mover, $\mathrm{L}$ is the distance traveled, and $\eta$ is the energy conversion efficiency of the engine that drives the mover.

According to the physics of locomotion on the earth in all media (water, land, and air), the horizontal force $\mathrm{F}$ is equal (in an order of magnitude sense) to $\mathrm{rMg}$, where $\mathrm{g}$ is the gravitational acceleration, $\mathrm{M}$ is the mass moved horizontally, and $\mathrm{r}$ is a factor that accounts for the medium in which the 


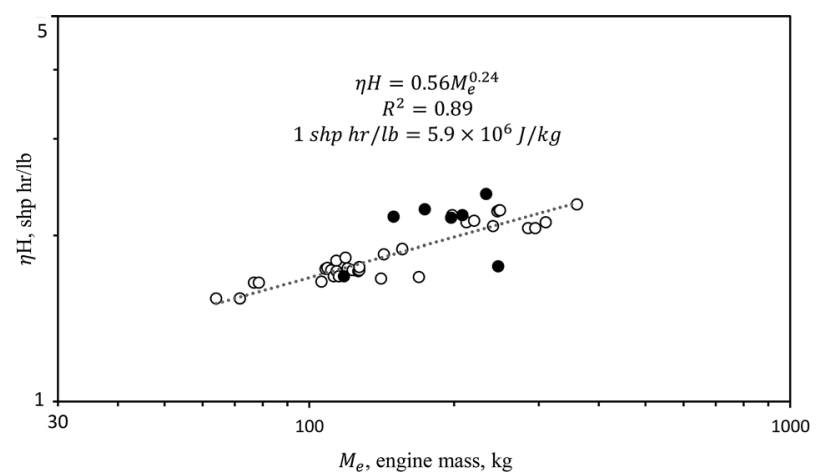

FIG. 4. Bigger engines are more efficient: the correlation between engine efficiency and engine size. $\mathrm{H}$ is the fuel heating value. ${ }^{42}$ In the indicated correlation, the military helicopter data (the black circles) were not included. If the military data are included, the correlation becomes $\eta H=0.53_{e}^{0.25}$, with $\mathrm{R}^{2}=0.79$.

movement occurs $(\mathrm{r} \sim 1$ in water, $\mathrm{r} \sim 0.1$ in air, and $0.1<\mathrm{r}<1$ on land). ${ }^{1,20}$

At the same time, the physics of economies of scale ${ }^{21}$ dictates that larger engines must be more efficient. This means that the efficiency $\eta$ increases slowly with $\mathrm{M}$, for example, in proportion with $\mathbf{M}^{\alpha}$, where the exponent $\alpha$ is positive and smaller than 1 so that the $\eta-\mathrm{M}$ curve is concave.

In a mature technology, the improvements in efficiency by changes in the design are marginal, $\eta$ tends toward a plateau, and consequently, $\alpha$ is considerably less than 1 . One example ( $\alpha \sim 1 / 4)$ is the convergent evolution of the engines for helicopters ${ }^{42}$ (Fig. 4). In summary, the amount of fuel spent during the movement of the mass $\mathrm{M}$ to the distance $\mathrm{L}$ on the earth is proportional to $\mathrm{M}^{1-\alpha} \mathrm{L}$, where $\alpha \ll 1$.

Consider now a large territory (for example, a country) swept by movers of many sizes $\left(\mathrm{M}_{0}<\mathrm{M}_{1}<\mathrm{M}_{2}<\ldots\right)$ and unequal numbers, such that the large are few and the small are many. Model the movement on the territory as a modular (constructal) architecture, where each larger construct is made of a number (n) of similar smaller constructs. This rule of construction is illustrated in Fig. 5 for $n=4$, which is the architecture based on quadrupling that is recognized now in river basins of all sizes. ${ }^{38}$ Other rules of construction $(n=2,3$, and 6$)$ lead to essentially the same conclusions, as we will see in Figs. 6 and 7.

The smallest construct is shown as a square of side $\mathrm{L}_{1}$. There are four small movers $\left(\mathrm{M}_{0}\right)$ that feed their freight to one large mover $\left(\mathrm{M}_{1}\right)$, which exits the $\mathrm{L}_{1} \times \mathrm{L}_{1}$ area. There are $\mathrm{N}_{1}$ areas that make up the whole territory. The $\mathrm{M}_{1}$ mover

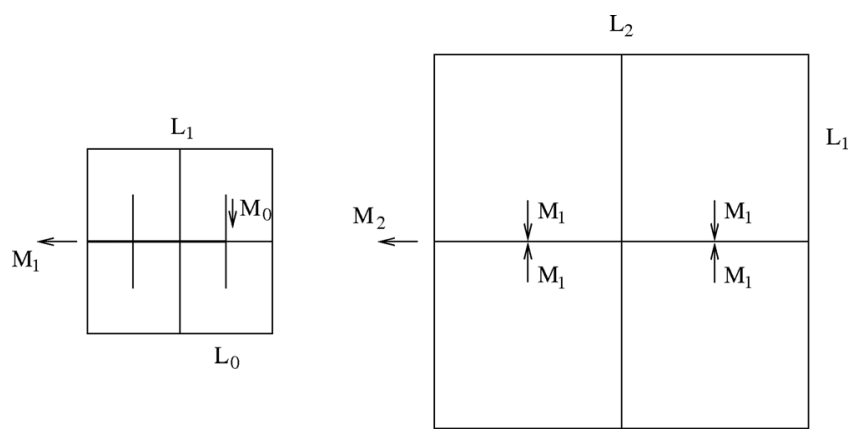

FIG. 5. Movement on an area as a sequence of progressively larger constructs formed by quadrupling.

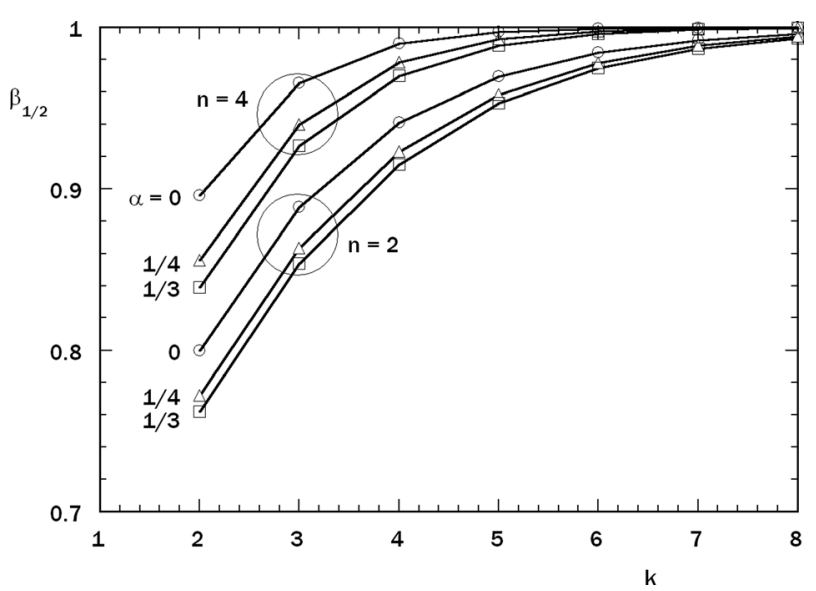

FIG. 6. The movement (wealth) is distributed nonuniformly among the movers. The total wealth is divided equally between two groups, the wealthier and the less wealthy. The fraction that the less wealthy half-group represents in the total population is reported as $\beta_{1 / 2}$ versus $\mathrm{n}$ and $\mathrm{k}$. The less wealthy group represents a much larger fraction of the total population than the wealthier. The graph also shows the effect of the economies of scale exponent $\alpha$. The unequal distribution of wealth becomes accentuated as the complexity (n, k) increases, and the movement covers the territory more completely.

travels a distance comparable with $\mathrm{L}_{1}$. Each $\mathrm{M}_{0}$ mover travels a distance comparable with $\mathrm{L}_{1} / 2$.

At the next larger scale, four movers of size $M_{1}$ feed their freight to one mover $\left(\mathrm{M}_{2}\right)$ that exits the territory of size $\mathrm{L}_{2} \times \mathrm{L}_{2}$, in which $\mathrm{L}_{2}=2 \mathrm{~L}_{1}$. There are $\mathrm{N}_{2}$ areas of size $\mathrm{L}_{2} \times \mathrm{L}_{2}$ that fit in the country. The rules of this construction toward larger constructs are evident

$$
\mathrm{L}_{\mathrm{i}+1}=2 \mathrm{~L}_{\mathrm{i}}, \quad \mathrm{N}_{\mathrm{i}+1}=\frac{\mathrm{N}_{\mathrm{i}}}{\mathrm{n}}, \quad \mathrm{M}_{\mathrm{i}+1}=\mathrm{nM}_{\mathrm{i}}
$$

The total fuel spent (i.e., the wealth $\mathrm{W}_{\mathrm{k}}$ ) is proportional to the sum

$$
\begin{aligned}
\mathrm{W}_{\mathrm{k}}= & \mathrm{N}_{1}\left[\mathrm{M}_{1}^{1-\alpha} \mathrm{L}_{1}+\mathrm{nM}_{0}^{1-\alpha} \mathrm{L}_{0}\right] \\
& +\mathrm{N}_{2}\left[\mathrm{M}_{2}^{1-\alpha} \mathrm{L}_{2}+\mathrm{nM}_{1}^{1-\alpha} \mathrm{L}_{1}\right]+\ldots \\
& +\mathrm{N}_{\mathrm{k}}\left[\mathrm{M}_{\mathrm{k}}^{1-\alpha} \mathrm{L}_{\mathrm{k}}+\mathrm{nM}_{\mathrm{k}-1}^{1-\alpha} \mathrm{L}_{\mathrm{k}-1}\right]
\end{aligned}
$$

where $\mathrm{k}$ is the number of levels of construction. Only two such levels are shown in Fig. 5. In view of the recurrence formulas (1), the total movement on the territory becomes

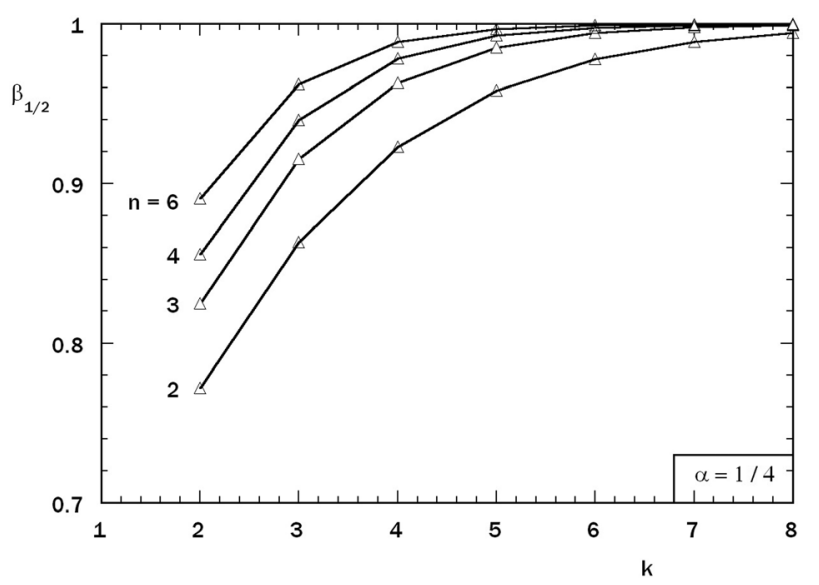

FIG. 7. The effect of the rule of construction (n) on the hierarchical distribution of movement on a fixed area. 


$$
\mathrm{W}_{\mathrm{k}}=\mathrm{fN}_{1} \mathrm{M}_{0}^{1-\alpha} \mathrm{L}_{0}\left[\gamma^{\mathrm{k}-1}+\gamma^{\mathrm{k}-2}+\ldots+\gamma+1\right]
$$

where

$$
\gamma=2 \mathrm{n}^{-\alpha}, \quad \mathrm{f}=\frac{1}{2} \mathrm{n}^{2-\alpha}+\mathrm{n}
$$

or, alternatively,

$$
\mathrm{W}_{\mathrm{k}}=\mathrm{fN}_{1} \mathrm{M}_{0}^{1-\alpha} \mathrm{L}_{0} \frac{\gamma^{\mathrm{k}}-1}{\gamma-1} .
$$

This sum represents the total movement over the constructs interconnected at all the scales, over the $\mathrm{k}$ levels of construction. This total is also proportional to the total wealth, cf. Fig. 1.

On the same territory, the population of movers (counted in the direction from the many small to the few large) is

$$
\mathrm{P}_{\mathrm{k}}=\mathrm{n}^{\mathrm{k}-1}+\mathrm{n}^{\mathrm{k}-2}+\ldots+\mathrm{n}+1
$$

or

$$
\mathrm{P}_{\mathrm{k}}=\frac{\mathrm{n}^{\mathrm{k}}-1}{\mathrm{n}-1}
$$

\section{UNEQUAL DISTRIBUTION}

Ask whether the total movement $\mathrm{W}_{\mathrm{k}}$ is distributed unevenly over the population $\mathrm{P}_{\mathrm{k}}$. The area constructs are numbered from the smallest to the largest: $1,2, \ldots, \mathrm{k}$. Imagine the intermediate size represented by the construct level $\mathrm{j}$, which accounts for all the movers of size $\mathrm{M}_{\mathrm{j}}$ and smaller. Their combined movement,

$$
\mathrm{W}_{\mathrm{j}}=\mathrm{f} \mathrm{N}_{1} \mathrm{M}_{0}^{1-\alpha} \mathrm{L}_{0} \frac{\gamma^{\mathrm{j}}-1}{\gamma-1}
$$

represents a fraction $(\varepsilon)$ of the total,

$$
\frac{\mathrm{W}_{\mathrm{j}}}{\mathrm{W}_{\mathrm{k}}}=\frac{\gamma^{\mathrm{j}}-1}{\gamma^{\mathrm{k}}-1}=\varepsilon \quad(0<\varepsilon<1) .
$$

The fraction $(\beta)$ of the total population that accounts for the movement fraction $\varepsilon$ is

$$
\frac{\mathrm{P}_{\mathrm{j}}}{\mathrm{P}_{\mathrm{k}}}=\mathrm{n}^{\mathrm{k}-\mathrm{j}} \frac{\mathrm{n}^{\mathrm{j}}-1}{\mathrm{n}^{\mathrm{k}}-1}=\beta \quad(0<\beta<1) .
$$

The construct $\mathrm{j}$ also divides the total population into two population groups, $\mathrm{P}_{\mathrm{j}}$ and $\left(\mathrm{P}_{\mathrm{k}}-\mathrm{P}_{\mathrm{j}}\right)$.

Assume that the total movement is divided equally between the two groups, $\varepsilon=1 / 2$. Therefore, we set and $\mathrm{W}_{\mathrm{j}}=$ $\frac{1}{2} \mathrm{~W}_{\mathrm{k}}$ and use Eq. (9) to determine the construct size $\mathrm{j}$. The construct of size $\mathrm{j}$ divides the movement between the two groups equally, smaller movers (constructs $1,2, \ldots, \mathrm{j}$ ) and larger movers $(\mathrm{j}+1, \ldots, \mathrm{k})$.

The population fraction represented by the individuals with less movement is obtained by substituting the calculated j into Eq. (10). The resulting fraction is labeled $\beta_{1 / 2}$ in Fig. 6, where the subscript $1 / 2$ indicates the equipartition of movement between the two population groups. Figure 6 was drawn by assuming $n=4$ and $n=2$ and varying $\alpha$ in the vicinity of $1 / 4$.

The individuals with less movement are the less wealthy who are thought to represent 80 percent of the total population, as reported by Pareto. ${ }^{24}$ This means that the model and analysis that led to Fig. 6 indicate that for $\beta_{1 / 2}=0.8$, there must be a relation between $\mathrm{n}$ and $\mathrm{k}$, for example, $\mathrm{n}=2$ if $\mathrm{k}=2$ or 3 .

The nonuniformity in the distribution of movement and wealth becomes more accentuated as the economy becomes more developed, i.e., as its flow architecture becomes more complex for the purpose of covering progressively smaller interstices of the overall (fixed) territory. This trend is evident in Fig. 7. All the $\beta_{1 / 2}$ values increase as the measures of complexity $(\mathrm{k}, \mathrm{n})$ increase.

The unequal distribution of wealth is further illustrated in Fig. 8, which on the abscissa shows the fraction of the total population $(\beta)$ that accounts for the fraction of total wealth $\varepsilon$ plotted on the ordinate. This figure was constructed according to Eqs. (9) and (10) by selecting a value of $\varepsilon$, calculating the corresponding $\mathrm{j}$, and finally the fraction of the population $\beta$.

Figure 8 was drawn for the special case $n=4$ and $\alpha=1 /$ 3 , which is representative of the cases plotted for $\beta_{1 / 2}$ in Figs. 6 and 7. Note that Figs. 6 and 7 refer to the special case of $\varepsilon=1 / 2$ that appears in Fig. 8. Once again, the distribution of wealth on the territory becomes less equal as the number of construction levels $\mathrm{k}$ increases, i.e., as the vascular flow architecture becomes more developed, more complex, and better spread over the population.

\section{RIVER BASINS}

We get a clearer and more familiar view of the natural phenomenon of unequal distribution of movement (wealth) by imagining a river basin that covers a fixed area with a dichotomous ( $n=2$, Fig. 9 top) design where every channel has two identical tributaries. The movement (the water flow rate) in one channel equals the movement in the tributaries. Next, we reason as follows:

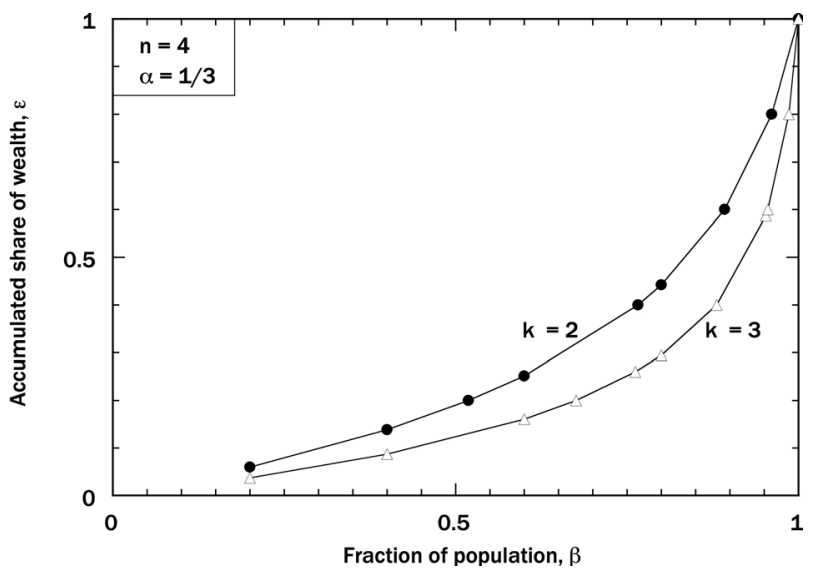

FIG. 8. The theoretical share of wealth $\varepsilon$ associated with the fraction $\beta$ of the total population. In this figure, $\varepsilon=1 / 2$ corresponds to the results plotted for $n=4$ and $\alpha=1 / 3$ in Fig. 6 . 

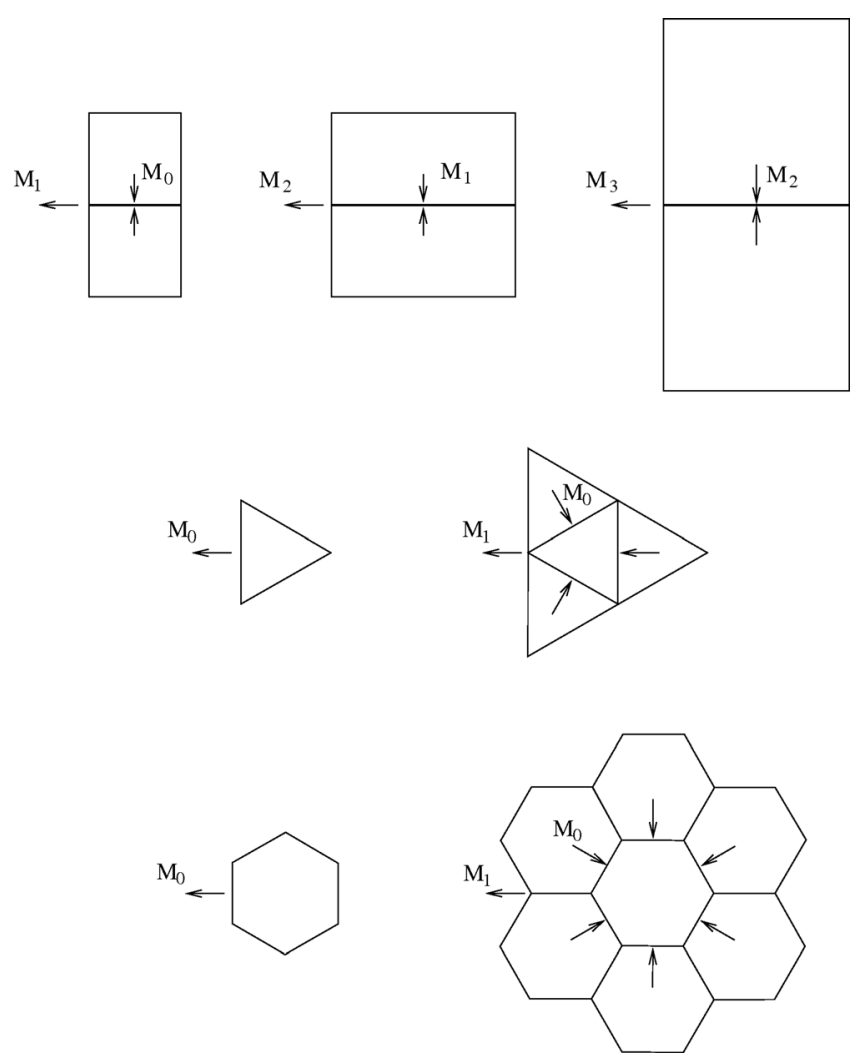

FIG. 9. Movement on areas constructed by doubling, tripling, and multiplication by six.

(i) If the area is covered by only three channels, then the architecture is Y-shaped, with one level of construction $(\mathrm{k}=1)$. The movement in the big channel equals the movement in the remaining two channels, and $\beta_{1 / 2}$ $=2 / 3$.

(ii) If the basin has seven channels, the architecture is more complex $(\mathrm{k}=2)$, the flow in the big channel equals the flow in the remaining six channels, and $\beta_{1 / 2}$ $=6 / 7$.

(iii) If the architecture is even more complex, with 15 channels, then $\mathrm{k}=3$, and $\beta_{1 / 2}=14 / 15$.

In the sequence (i)-(iii) we see that as we saw earlier in Fig. 7 , it takes a relatively modest complexity $(\mathrm{k}=2$ or 3$)$ for the measure of inequality $\left(\beta_{1 / 2}\right)$ to reach levels even higher than the 80 percent observed by Pareto. ${ }^{24}$ This conclusion is the same for constructions based on doubling (Fig. 9 top) and quadrupling (Fig. 5). The lower part of Fig. 9 suggests two alternative constructions, based on tripling and on area multiplication by six.

\section{CONCLUSIONS}

The chief conclusion derived from physics, is that inequality is nonuniform as a manifestation of the universal natural phenomenon of evolution. This phenomenon belongs in physics. Movement is a natural evolutionary design phenomenon that changes toward flow architectures that provide progressively greater access over the territory that generates the power that drives the movement. This evolutionary design happens naturally across the board, from the river basins of the water circuit driven by the sun, to all human life driven by power from fuels, the sun, and food.

On this physics foundation, it pays to re-examine and update the observations presented in Figs. 1-3, which served as a starting point for the present theory:

First, as commented while describing Fig. 1, every point - every population group - is migrating upward. This is now validated in Fig. 10, which focuses on the wealthy end of Fig. 1, and shows how the data have migrated upward from 2006 to 2014. The migration is consistently upward, and it is of two kinds. Developing countries such as China and Turkey have migrated upward along the diagonal. Developed countries have migrated upward and to the left. This second group has become not only wealthier but also more efficient, by creating more movement per unit of fuel spent.

The new aspect revealed by Fig. 10 is that the evolutionary design is such that the tendency toward greater movement goes hand in hand with the tendency toward more efficient technologies that enable the movement, and vice versa, cf. Jevon's paradox. Both tendencies are manifestations of the constructal law: this combination is what easier (greater) access represents. ${ }^{1}$

Second, the latest data from the World Bank ${ }^{41}$ offer additional support for the unequal distribution of wealth, which emerged in Fig. 8. The latest data are presented in Fig. 11, which on the ordinate shows the share $\varepsilon$ of the annual income of the population fraction $\beta$. The comparison between Fig. 11 and Fig. 8 is not exact because income (Fig. 11) is not the same as movement (Fig. 8) or wealth (Fig. 1). Nevertheless, the comparison is qualitatively valid, and it shows that income is distributed unequally everywhere. The distribution curve is convex, as anticipated in Fig. 8. Consequently, the present theory also predicts the Lorenz-type distribution of income inequality, which has been adopted empirically for a century.

Figure 11 further shows is that more advanced countries have relatively straighter convex curves, i.e., their income is distributed more equally. This new aspect is an invitation to expanding the present "economics as physics" theory into the domain of government. All distributions are happening

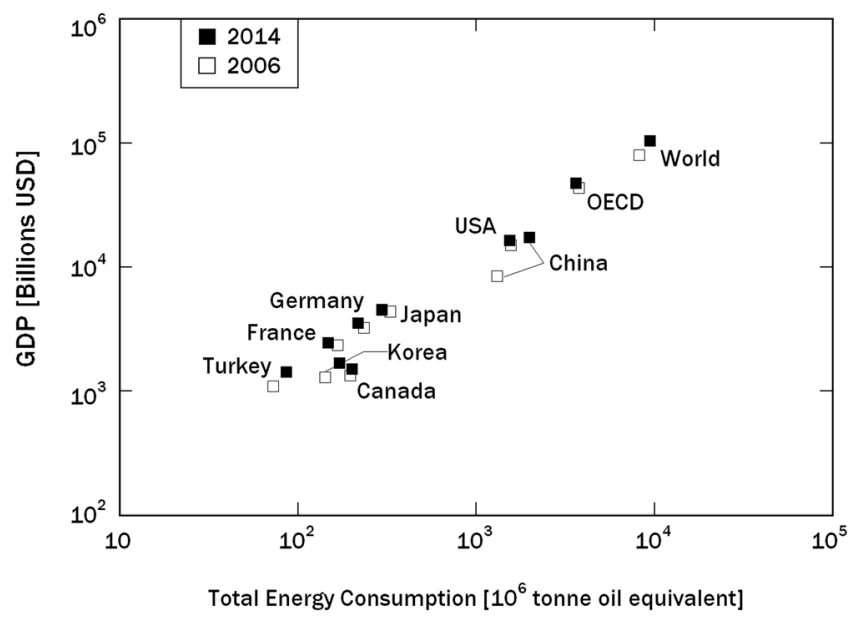

FIG. 10. The upward migration of the data of Fig. 1, from 2006 to 2014 (Refs. 18, 40, and 41). 


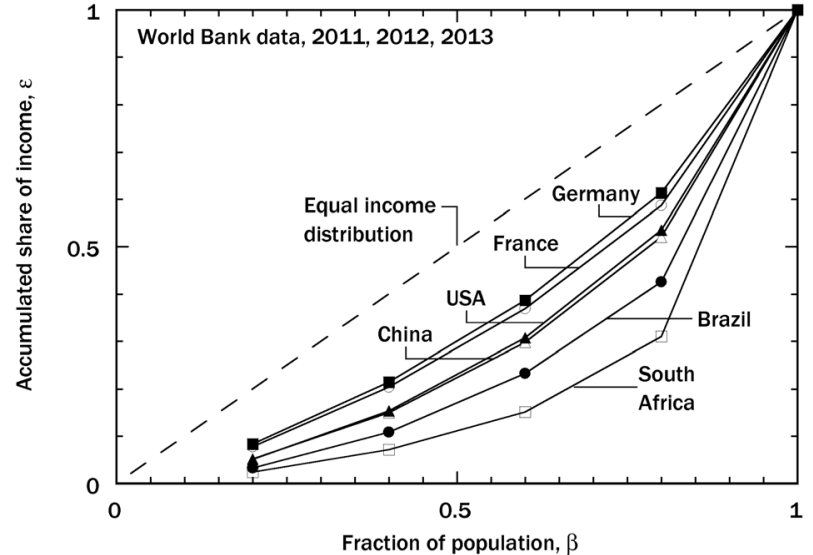

FIG. 11. The accumulated share of income $(\varepsilon)$ held by the fraction of the population $(\beta)$, cf. Fig. 8. Data are adapted from Ref. 41. (The World Bank Development Indicators). Note from the World Bank, Development Research Group: data are based on primary household survey data obtained from government statistical agencies and World Bank country departments. Data for high-income economies are from the Luxembourg Income Study database. For more information and methodology, see PovcalNet (http://iresearch.worldbank.org/PovcalNet/index.htm).

naturally, yet their degree of "inequality" can be controlled by the rule of law, which is a package of evolutionary design features that so far are not present in the theory advanced in this article.

Another starting point for further work along this theoretical line is the observation that the population is increasing at all levels, on a finite area, and globally. This introduces a time-dependent aspect to the inequality in wealth distribution. Population growth may also contribute to the physics that underpins Jevon's paradox, as the increase in fuel consumption may be related to the increase in fuel demand caused by population growth. The reverse is also true because with more fuel consumption (with more power), the global flow system of human life increases and spreads in accord with its S-curve history and future. ${ }^{1,43}$ The S-curve phenomenon means that every point-area flow spreads over its territory in three successive phases, slow-fast-slow. This is why fuel consumption and movement (such as miles driven in the U.S. annually) cannot increase indefinitely, as shown in Fig. 7.4 of Ref. 1.

At bottom, evolution (change in flow architecture) is favored on the same physics basis in economics, geophysics, animate, and inanimate systems. The design change that facilitates global flow is adopted and persists. It "survives." This evolution is evident in economics. The invention of money was a dramatic change for facilitating the flow of traded goods, a huge change relative to trading in nature. The adoption of a single currency in the USA, and more recently in the Euro zone, is a more recent example. Regional free trade agreements between countries and the spreading of English, Latin script, and the Internet lead to increased movement.

Evolution unites physics with economics and extends the reach of the physics law of evolution over the phenomena of social organization, economies of scale, ${ }^{44}$ and movement on the globe. In addition to the constructal-law reviews noted earlier, $2,3,12-16,28-37$ Ref. 45 reviewed examples of the predictive power of the constructal law as evidence of its falsifiability in accord with the test proposed by Ellis and Silk. ${ }^{46}$

\section{ACKNOWLEDGMENTS}

Professor Bejan's work was supported by the U. S. National Science Foundation. Professor Errera's work was sponsored by the Federal University of Parana, Brazil.

${ }^{1}$ A. Bejan, The Physics of Life: The Evolution of Everything (St. Martin's Press, New York, 2016).

${ }^{2}$ G. Lorenzini and C. Biserni, "The Constructal Law: From design in nature to social dynamics and wealth as physics," Phys. Life Rev. 8, 259-260 (2011).

${ }^{3}$ T. Basak, "The law of life: The bridge between physics and biology," Phys. Life Rev. 8, 249-252 (2011).

${ }^{4}$ W. M. Saslow, "An economic analogy to thermodynamics," Am. J. Phys. 67(12), 1239-1247 (1999).

${ }^{5}$ M. Smerlak, "Thermodynamics of inequalities: From precariousness to economic stratification," Phys. A: Stat. Mech. Appl. 441, 40-50 (2016).

${ }^{6}$ M. Karpiarz, P. Fronczak, and A. Fronczak, "International trade network: Fractal properties and globalization puzzle," Phys. Rev. Lett. 113, 248701 (2014).

${ }^{7} \mathrm{G}$. Weisbuch and S. Battiston, "From production networks to geographical economics," J. Econ. Behav. Organ. 64, 448 (2007).

${ }^{8}$ A. Bejan and S. Lorente, "Constructal law of design and evolution: Physics, biology, technology and society,” J. Appl. Phys. 113, 151301 (2013).

${ }^{9}$ Y. Chen, "Maximum profit configurations of commercial engines," Entropy 13, 1137-1151 (2011).

${ }^{10} \mathrm{H}$. Temple, Théorie générale de la nation, L'architecture du monde (L'Harmattan, Paris, 2014).

${ }^{11}$ W. C. Frederick, Natural Corporate Management: from the Big Bang to Wall Street (Greenleaf Publishing, Sheffield, UK, 2012).

${ }^{12}$ P. Kalason, Le Grimoire des Rois: Théorie Constructale du Changement (L'Harmattan, Paris, 2007).

${ }^{13}$ P. Kalason, Épistémologie Constructale du Lien Cultuel (L'Harmattan, Paris, 2007).

${ }^{14} \mathrm{~A}$. F. Miguel, "The physics principle of the generation of flow configuration," Phys. Life Rev. 8, 243-244 (2011).

${ }^{15}$ A. H. Reis, "Design in nature, and the laws of physics," Phys. Life Rev. 8, 255-256 (2011).

${ }^{16}$ L. Wang, "Universality of design and its evolution," Phys. Life Rev. 8, 257-258 (2011).

${ }^{17} \mathrm{G}$. Weisbuch and Y. Louzoun, "Sustainable development and spatial in homogeneities," J. Stat. Phys. 151, 475-493 (2013).

${ }^{18} \mathrm{See}$ http://www.iea.org/publications/freepublication/publication/energystatistics-manual.html for "IEA Statistics C OECD/IEA 2014."

${ }^{19}$ J. B. Alcott, "Jevon's paradox," Ecol. Econ. 54, 9-21 (2005).

${ }^{20} \mathrm{~A}$. Bejan and J. H. Marden, "Unifying constructal theory for scale effects in running, swimming and flying," J. Exp. Biol. 209, 238-248 (2006).

${ }^{21} \mathrm{~A}$. Bejan, "Why the bigger live longer and travel farther: animals, vehicles, rivers and the winds," Sci. Rep. 2, 594 (2012).

${ }^{22}$ A. Bejan, Advanced Engineering Thermodynamics, 4th ed. (Wiley, Hoboken, 2016).

${ }^{23}$ A. Bejan, Convection Heat Transfer, 4th ed. (Wiley, Hoboken, 2013).

${ }^{24}$ V. Pareto, "Cours d'Économie Politique, Vol. II ('The Law of Income Distribution') (1897)," in The Economics of Vilfredo Pareto, edited by R. Cirillo (Frank Cass and Co., 1979), pp. 80-87.

${ }^{25}$ A. Bejan, "Street network theory of organization in nature," J. Adv. Transp. 30(2), 85-107 (1996).

${ }^{26} \mathrm{~A}$. Bejan, "Constructal-theory network of conductive paths for cooling a heat generating volume," Int. J. Heat Mass Transfer 40(4), 799-816 (1997).

${ }^{27}$ A. Bejan, Advanced Engineering Thermodynamics, 2nd ed. (Wiley, New York, 1997)

${ }^{28}$ L. Chen, "Progress in study on constructal theory and its applications," Sci. China, Ser. E: Technol. Sci. 55(3), 802-820 (2012).

${ }^{29}$ A. F. Miguel, "Natural flow systems: acquiring their constructal morphology," Int. J. Design Nature Ecodyn. 5, 230-241 (2010). 
${ }^{30}$ A. H. Reis, "Constructal theory: From engineering to physics, and how systems develop shape and structure," Appl. Mech. Rev. 59, 269-282 (2006).

${ }^{31}$ A. H. Reis, "Use and validity of principles of extremum of entropy production in the study of complex systems," Ann. Phys. 346, 22-27, 40 (2014).

${ }^{32}$ Y. Ventikos, "The importance of the constructal framework in understanding and eventually replicating structure in tissue," Phys. Life Rev. 8, 241-242 (2011).

${ }^{33}$ A. Kremer-Marietti, The Constructal Principle (DOGMA, 2007).

${ }^{34}$ J. D. Bachta and A. Kremer-Marietti, Trois Ètudes sur la Loi Constructale d'Adrian Bejan (L'Harmattan, Paris, 2008).

${ }^{35}$ Constructal Theory and Multi-Scale Geometries: Theory and Applications in Energetics, Chemical Engineering and Materials, edited by D. QueirosConde and M. Feidt (Les Presses de L'ENSTA, Paris, 2009).

${ }^{36}$ L. A. O. Rocha, Convection in Channels and Porous Media: Analysis, Optimization, and Constructal Design (VDM Verlag, Saarbrücken, 2009).

${ }^{37}$ G. Lorenzini, S. Moretti, and A. Conti, Fin Shape Optimization Using Bejan's Constructal Theory (Morgan \& Claypool Publishers, 2011).
${ }^{38}$ A. Bejan, S. Lorente, A. F. Miguel, and A. H. Reis, "Constructal theory of distribution of river sizes, section 13.5," in Advanced Engineering Thermodynamics, 3rd ed., edited by A. Bejan (Wiley, Hoboken, 2006).

${ }^{39}$ International Energy Agency, Key World Energy Statistics 2006 (IEA/ STEDI Media, Paris, 2006).

${ }^{40}$ See http://www.iea.org/statistics/ for more information about International Energy Agency.

${ }^{41}$ See http://databank.worldbank.org/data/home.aspx for more information about The World DataBank.

${ }^{42}$ R. Chen, C. Y. Wen, A. Bejan, and S. Lorente, "The evolution of helicopters," J. Appl. Phys. 120, 014901 (2016).

${ }^{43}$ A. Bejan and S. Lorente, "The constructal law origin of the logistics S curve,” J. Appl. Phys. 110, 024901 (2011).

${ }^{44}$ A. Bejan, A. Almerbati, and S. Lorente, "Economies of scale: The physics basis," J. Appl. Phys. 121, 044907 (2017).

${ }^{45}$ A. Bejan and R. W. Wagstaff, "The physics origin of the hierarchy of bodies in space," J. Appl. Phys. 119, 094901 (2016).

${ }^{46}$ G. Ellis and J. Silk, "Defend the integrity of physics," Nature 516, 321-323 (2014) 